\title{
BMJ Open Patient safety issues and concerns in Bhutan's healthcare system: a qualitative exploratory descriptive study
}

\author{
Rinchen Pelzang, ${ }^{1}$ Alison M Hutchinson ${ }^{1,2}$
}

To cite: Pelzang R, Hutchinson AM. Patient safety issues and concerns in Bhutan's healthcare system: a qualitative exploratory descriptive study. BMJ Open 2018;8:e022788. doi:10.1136/ bmjopen-2018-022788

- Prepublication history for this paper is available online. To view these files, please visit the journal online (http://dx.doi org/10.1136/bmjopen-2018022788).

Received 9 March 2018 Revised 6 June 2018 Accepted 18 June 2018

Check for updates

(c) Author(s) (or their employer(s)) 2018. Re-use permitted under CC BY-NC. No commercial re-use. See rights and permissions. Published by BMJ.

${ }^{1}$ Centre for Quality and Patient Safety Research, School of Nursing and Midwifery, Deakin University, Geelong, Victoria, Australia

${ }^{2}$ Deakin Centre for Quality and Patient Safety Research, Monash Health, Melbourne, Victoria, Australia

Correspondence to Dr Rinchen Pelzang; rpelzang1970@gmail.com

\begin{abstract}
Objectives To investigate what healthcare professionals perceived and experienced as key patient safety concerns in Bhutan's healthcare system.

Design Qualitative exploratory descriptive inquiry.

Settings Three different levels of hospitals, a training institute and the Ministry of Health, Bhutan.

Participants In total, 140 healthcare professionals and managers.
\end{abstract}

Methods Narrative data were collected via conversational in-depth interviews and Nominal Group Meetings. All data were subsequently analysed using thematic analysis strategies.

Results The data revealed that medication errors, healthcare-associated infections, diagnostic errors, surgical errors and postoperative complications, laboratory/blood testing errors, falls, patient identification and communication errors were perceived as common patient safety concerns. Human and system factors were identified as contributing to these concerns. Instituting clinical governance, developing and improving the physical infrastructure of hospitals, providing necessary human resources, ensuring staff receive patient safety education and promoting 'good' communication and information systems were, in turn, all identified as processes and strategies critical to improving patient safety in the Bhutanese healthcare system.

Conclusion Patient safety concerns described by participants in this study were commensurate with those identified in other low and middle-income countries. In order to redress these concerns, the findings of this study suggest that in the Bhutanese context patient safety needs to be conceptualised and prioritised.

\section{INTRODUCTION}

WHO has recognised patient safety as a global problem and positioned it as a worldwide endeavour, seeking to bring benefits to patients in countries rich and poor, developed and developing alike. ${ }^{1}$ It is estimated that each year millions of patients worldwide suffer disabilities, injuries or death due to unsafe medical care, and that around $50 \%$ of these harmful outcomes are preventable. ${ }^{23}$ The incidence and impact of preventable harmful events are particularly burdensome in low-income, middle-income and transitional-income countries. ${ }^{23}$

\section{Strengths and limitations of this study}

A strength of this study is the qualitative exploratory descriptive approach used, a pragmatic approach which enabled capture of participants' experiences of the real-world context.

- The detailed account of the problem and the capture of meaningful characteristics related to real-life events is a strength of the study.

- A further strength of the study is the inclusion of healthcare professionals from a range of disciplinary backgrounds across three levels of hospitals.

- The reliance on patient safety concepts, theories and practices that have been developed and applied in high-income resource-rich nations is the main limitation of this study.

- The large quantity of data generated required decisions about inclusion and exclusion of data, which may have resulted in the loss of some material.

Despite patient safety being positioned by WHO as a global priority, improving patient safety outcomes in resource-poor nations is challenging. One reason for this is a lack of reliable data to quantify the burden of unsafe patient care and, in turn, inform patient safety improvement initiatives. ${ }^{4}$ Another reason is that most current data on patient safety come from developed or high-income countries, where the healthcare contexts are different and where processes for improving patient safety outcomes cannot be readily transferred to other (less resourced) countries and their local healthcare settings. ${ }^{5}{ }^{6}$ Even so, it is estimated that rates of adverse events in low-income countries are higher than those of high-income countries. For example, the risk of healthcare-associated infections (HAIs) in low-income countries is estimated to be 20 times higher than in high-income countries. ${ }^{7}$ Similarly, research evidence suggests the prevalence of preventable surgical adverse event rates in low-income 
countries is five times more than in high-income countries. ${ }^{8}$

Most adverse events have been found to be associated with human (staff) factors and system (organisational) factors. ${ }^{9-11}$ Human (staff) factors include slips, lapses, violations and mistakes made by healthcare professionals (such as nurse, physicians, surgeons, pharmacists, anaesthetists) due to aberrant mental processes such as inattention, forgetfulness, carelessness, negligence, recklessness, poor motivation and lack of competency (knowledge, skills and attitude) ${ }^{12-17}$ In medical and nursing literature, competency is classified according to knowledge, skills and attitudes. ${ }^{17-22}$ Knowledge relates to healthcare professionals' ability to recognise and understand the potential patient safety features and/or strategies (ie, correctly prescribing medication-right drug, for the right reasons). Skills relate to healthcare professionals' ability to perform clinical tasks correctly to reduce risk of harm to patients (ie, the correct preparation and administration of injections, the prevention of cross-infection, accurately checking vital signs and taking a full patient history). Finally, attitudes relate to healthcare professionals' ability to value the patient safety prevention strategies and follow them (ie, value own role in preventing errors by following standard protocols). System (organisational) factors relate to the conditions under which individuals work and can be used to build defences to avert errors or mitigate their effects. ${ }^{13}$ System (organisational) factors include effective patient safety and clinical governance, financial resources, educational system and hospital design.

In Bhutan, patient safety issues and concerns are not well documented or known. To date, there have been no published studies scoping either the nature or impact of patient safety concerns in Bhutan's healthcare system. Thus, at this time, as noted in the WHO Global priorities for patient safety research, ${ }^{4}$ the main option for informing strategies aimed at improving patient safety in Bhutan is to scope stakeholders' perceptions and personal experiences of patient safety processes. It is anticipated that by undertaking preliminary scoping work a better understanding can be gained of the nature and extent of patient safety concerns in the Bhutanese context and what is required to redress these.

The aim of this study was to scope and describe what stakeholders (clinicians, health service managers, educators and policymakers) perceived and personally experienced as being the most common patient safety concerns in the Bhutanese healthcare system. The three research questions guiding the study were

- What are healthcare professionals' and managers' knowledge, perceptions, understanding and experiences of patient safety in Bhutan's hospitals?

- What factors do healthcare professionals and managers identify as most contributing to patient safety concerns in Bhutan's hospitals?
- What strategies do healthcare professionals and managers suggest are needed in order to address the patient safety issues and concerns they identified?

\section{METHODS}

\section{Study design}

This study was undertaken as a naturalistic inquiry using a qualitative exploratory descriptive (QED) research approach. The QED research approach assists researchers to gain an understanding of the realworld context as it is experienced by the participants; that is, what is working and what is not working. ${ }^{23}$ The approach enables the researcher to obtain a detailed account of the problem of concern and capture meaningful characteristics related to real-life events. ${ }^{24}$ Most importantly, QED research is appropriate in situations where the problem is not known or the problem is too complex to be captured by other methods (eg, questionnaire survey).$^{23}$ QED research is considered to be a highly pragmatic approach that enables the answering of concrete and practical 'what' kinds of question, ${ }^{23} 25$ such as those addressed in this study.

\section{Settings and participants}

The study was conducted in 2013 in three levels of hospital (district, regional referral and national referral), a training institute and the Ministry of Health in Bhutan. ${ }^{26}$ A sample of 94 participants (doctors, nurses, ward managers, senior managers and health assistants) was purposively recruited and interviewed. Additionally, 46 healthcare professionals participated in Nominal Group Meetings (NGMs) (table 1).

\section{Patient and public involvement}

As the aim of this study was to scope and describe what healthcare professionals perceived and personally experienced as being the most common patient safety concerns in the Bhutanese healthcare system, no patients were involved in this study.

\section{Data collection procedure}

Data were collected via in-depth interviews $(n=94)$ and NGMs $(n=5)$. Participants for in-depth interviews were invited through direct contact, flyers posted on staff noticeboards and invitation letters sent to participating wards/institutes. They were interviewed individually using broad semistructured interview questions to elicit knowledge, perceptions and experiences of patient safety in Bhutan. Participants for NGMs were nominated by their managers and the NGMs were conducted in different groups according to criterion-based characteristics such as doctors, nurses and managers. To facilitate smooth NGMs, a nominal group task statement form, which specified the exploratory questions, was used to list the critical elements of the patient safety issues. Duration of individual interviews and NGMs ranged from 45 to $120 \mathrm{~min}$. 


\begin{tabular}{|c|c|c|c|}
\hline $\begin{array}{l}\text { Participant } \\
\text { group }\end{array}$ & Characteristic & & \\
\hline \multirow{14}{*}{$\begin{array}{l}\text { In-depth } \\
\text { interview } \\
\text { participants }\end{array}$} & Gender & $N(\%)$ & \\
\hline & Male & 56 (59.6\%) & \\
\hline & Female & 38 (40.4\%) & \\
\hline & Age & Years & Mean (years) \\
\hline & Minimum & 23 & 36.7 \\
\hline & Maximum & 60 & \\
\hline & $\begin{array}{l}\text { Professional } \\
\text { qualification }\end{array}$ & $N(\%)$ & \\
\hline & Certificate & $6(6 \%)$ & \\
\hline & Diploma & 33 (35\%) & \\
\hline & Bachelor & $23(25 \%)$ & \\
\hline & Master & 32 (34\%) & \\
\hline & Length of service & Years & Mean (years) \\
\hline & Minimum & 0.5 & 12.7 \\
\hline & Maximum & 29 & \\
\hline \multirow{14}{*}{$\begin{array}{l}\text { Nominal } \\
\text { Group Meeting } \\
\text { participants }\end{array}$} & Gender & $N(\%)$ & \\
\hline & Male & 24 (52\%) & \\
\hline & Female & $22(47.8 \%)$ & \\
\hline & Age & Years & Mean (years) \\
\hline & Minimum & 24 & 35.6 \\
\hline & Maximum & 50 & \\
\hline & $\begin{array}{l}\text { Professional } \\
\text { qualification }\end{array}$ & $N(\%)$ & \\
\hline & Certificate & $2(4.34 \%)$ & \\
\hline & Diploma & 26 (56.5\%) & \\
\hline & Bachelor & $9(19.6 \%)$ & \\
\hline & Master & $9(19.6 \%)$ & \\
\hline & Length of service & Years & Mean (years) \\
\hline & Minimum & 0.5 & 10.2 \\
\hline & Maximum & 22 & \\
\hline
\end{tabular}

\section{Data analysis}

Narrative data obtained from interviews and NGMs were analysed using the following steps: verbatim transcription of audio-recordings, active reading of transcripts, making notes on general themes, re-reading transcripts, comparing transcripts with key themes and concepts, making categories describing all aspects of the content, excluding unusable content or fillers, re-reading transcripts alongside the finally agreed list of categories and making adjustments as necessary. ${ }^{27}$ The data collected and analysed are reported and discussed in aggregate in this article; no additional data are available.

\section{RESULTS}

This study revealed eight major patient safety concerns, possible factors contributing to them and recommendations for strategies which could be used for addressing the concerns identified. The results are presented according to these areas.

\section{Patient safety issues and concerns}

Participants identified the following patient safety issues: medication/drug errors, HAIs, surgical errors and postoperative complications, diagnostic errors, laboratory/ testing errors, injurious falls, communication errors and patient identification errors (themes and supporting quotes are provided in table 2 ).

\section{Medication/drug errors}

Medication error was the most common patient safety concern identified. Errors included administering wrong drugs to the wrong patient, administering drugs that had passed their expiry date, giving the wrong drug dose, continuation of drugs for unjustified periods of time and drug omissions (failure to administer prescribed drugs). 'Irrational' use of drugs was also described, manifested as prescribing of large quantities of drugs; high drug doses that could not be justified or were outside recommended doses; and antibiotics to treat non-bacterial infections or viral conditions.

\section{Healthcare-associated infections}

Postsurgery wound infections and urinary tract infections (due to healthcare professionals not adhering to sterile technique during catheterisation) were the two main HAIs identified.

\section{Surgical errors and postoperative complications}

Notable among the surgical-related patient safety concerns were retention of foreign objects (eg, gauze or instruments). In some instances, surgical errors resulted in mortality.

\section{Diagnostic errors}

Errors in diagnosis were perceived as common (eg, wrongly diagnosing a patient as having tuberculosis, when they had cancer and vice versa).

\section{Laboratory/blood testing errors}

Incompatible blood transfusion errors were reported. Common laboratory/blood testing errors included performing wrong or unnecessary blood investigations, and issuing wrong laboratory reports.

\section{Fall injuries}

This involves patients falling from beds and trolleys.

\section{Communication errors}

Communication errors, verbal abuse and/or rude behaviour towards patients, and failure to communicate clearly to patients about their disease and treatment were identified.

\section{Patient identification errors}

The lack of a formal patient identification system was reported. This was considered particularly problematic since Bhutanese people often have the same or similar 
Table 2 Patient safety issues and concerns

Themes

Healthcare-associated infections

\section{Participant statements}

'I think the most common is errors in drug doses and medications. [...] medication error includes errors in giving IV fluids like sometimes wrong IV fluids, wrong rate of administration-improper calculation of the drop rates' (Medical doctor).'

'[...] misuse of antibiotics - sometimes you continue antibiotics even for cough and cold where it is not required. They [doctors] use high dosage of different antibiotics for organisms that are not sensitive.' (Medical doctor)

'Infection is definitely an issue. Previously where I used to work, [...] in a small district hospital, usually patient with small surgery-minor surgery was getting postsurgery wound infection. Wound not healing faster.' (Senior manager)

'We do come across hospital acquired infections - people especially with long term hospitalisation tend to get urinary tract infections. I don't know how people [healthcare providers] are handling the catheterisation process.' (Medical doctor)

\begin{tabular}{|c|c|}
\hline $\begin{array}{l}\text { Surgical errors and postoperative } \\
\text { complications }\end{array}$ & $\begin{array}{l}\text { 'We always hear from the operation theatre that some gauze pieces or some } \\
\text { instrument has been left inside.' (Nurse) }\end{array}$ \\
\hline Diagnostic errors & $\begin{array}{l}\text { 'They [doctors] misdiagnose and then sometimes they give wrong medication which } \\
\text { I have seen in one case that the patient really had adverse effect.' (Nurse) }\end{array}$ \\
\hline Laboratory/blood testing errors & $\begin{array}{l}\text { 'Sometimes there are few laboratory mistakes. I don't know whether it is the printing } \\
\text { mistakes, sometimes we send two samples almost within } 2 \text { to } 3 \text { hours gap and the } \\
\text { report come completely different. Maybe because staff are giving wrong sample } \\
\text { for the other patient or is the printing mistake from the lab [...]. We have cases } \\
\text { like same patient having done the same investigations in few hours showed vast } \\
\text { difference in the reading.' (Nurse) }\end{array}$ \\
\hline Fall injuries & $\begin{array}{l}\text { 'While patient is transferred in the trolley there was one incident where the patient } \\
\text { went off the trolley. And then few times we have heard patient falling from the bed. } \\
\text { So fall is common.' (Ward manager) }\end{array}$ \\
\hline Communication errors & $\begin{array}{l}\text { 'Most of the time the misunderstanding that happens between the patient and } \\
\text { the staff is due to lack of adequate communication. Many a times what we have } \\
\text { done is for example probably not spend enough time on that part-explaining the } \\
\text { diagnosis, where is the problem, what medicine you are prescribing, how you need } \\
\text { to take that medicine, what are the side effects of the medicines, all these things, } \\
\text { you know.' (Senior manager - NGM1) } \\
\text { 'I think one complaint we hear is that of verbal abuse by the health professionals to } \\
\text { patients and their relatives.' (Senior manager) }\end{array}$ \\
\hline Patient identification errors & $\begin{array}{l}\text { 'I think one pertinent one is for lack of patient identification marks. Our Bhutanese } \\
\text { have similar names and then that can lead to, during procedures in rush hours, } \\
\text { doing procedures in a wrong patient.' (Medical doctor) }\end{array}$ \\
\hline
\end{tabular}

names. A major consequence of this was the risk and incidence of patients receiving the wrong treatment or procedure.

\section{Factors contributing to patient safety concerns}

Human (staff) and system factors were identified as the main contributing factors to patient safety concerns (themes and supporting quotes are presented in table 3).

\section{Human (staff) factors}

Lack of patient safety competency

The most commonly cited factor contributing to patient safety concerns was healthcare professionals' lack of patient safety competencies, encompassing lack of knowledge of patient safety principles and processes, not having the necessary skills to practice safely, and not displaying the 'right' attitude.
Knowledge

Lack of knowledge about quality improvement and patient management processes was identified as a major contributing factor to patient safety concerns. Medication errors and HAIs were linked to healthcare professionals' lacking requisite knowledge about medicines/drugs and infection control.

\section{Skills}

Healthcare professionals' lack of patient assessment skills, for example, not checking vital signs, not taking a detailed patient history or failure to review a patient's history, were perceived as contributing to errors such as wrong patient diagnoses and treatment.

\section{Attitudes}

The most prominent issue identified was a complacent attitude among healthcare professionals (eg, taking 
Table 3 Factors contributing to patient safety concerns

\begin{tabular}{|c|c|}
\hline Themes & Participant statements \\
\hline \multicolumn{2}{|c|}{ Human (staff) factors } \\
\hline \multicolumn{2}{|c|}{ Lack of patient safety competency } \\
\hline Knowledge & $\begin{array}{l}\text { 'Sometimes the medication errors usually happen because they [staff] aren't aware of the right } \\
\text { method to be given. For example, there are some medications like [name of drugs withheld] which } \\
\text { are really painful and it should not be given direct bolus, but it should rather be given as infusion. } \\
\text { [...] It so happens that they are given bolus and then we have to be facing a problem and solving } \\
\text { it.' (Nurse-NGM5) }\end{array}$ \\
\hline Skills & $\begin{array}{l}\text { 'One issue is - usually the patients are seen in [...] OPD [Out-patient Department] and they are } \\
\text { sent here [to the ward]. So they [clinicians] did not monitor the vital signs and then we had some } \\
\text { incidents. [...] [one patient] did not have vital signs monitored and did not have [Blood Pressure } \\
\text { checked] - actually the patient was 'walking dead'. Then we had to manage here in the ward and } \\
\text { then ultimately send to ICU.' (Ward manager) }\end{array}$ \\
\hline Attitudes & $\begin{array}{l}\text { 'It is the attitude [of healthcare providers] sometimes.' (Ward manager) } \\
\text { 'If I have to say, I think certain procedures are done by people who are not very cautious about } \\
\text { taking precautions. For example, as a medical student we knew that we have to take lots of } \\
\text { precaution even to insert a catheter but now I see that it is being done very casually. I don't think } \\
\text { people are really taking care of the proper sterile techniques and all.' (Medical doctor) }\end{array}$ \\
\hline
\end{tabular}

\section{System (organisational) factors}

Lack of resources
Lack of policies, guidelines
and protocols on patient
safety

'Contribution for medication error maybe due to the shortage of nursing staff where while they are preparing the medicine, they have to go and attend the other critical cases, if any.' (Senior manager)

'I think the most common patient safety issue is establishing diagnosis. I find it as a major issue because patients are not properly followed up and then adequate investigating facilities are not available and we lose patient in between.' (Nurse)

'One is the standard management of patient. That depends on individual specialists and individual doctors. A major crux of the thing is how to come to a proper diagnosis and what line of treatment. So, highly qualified specialists have their own line of management which some specialists don't agree.' (Senior manager)

Poor communication and collaboration

Lack of management support and governance

\section{'When I talk about the patient safety one thing is that there is a gap in between doctors and} nurses because they prescribe antibiotics and it goes more than 20 to 30 days. [...] Doctors, when they prescribe the drugs in ward, most of the doctors they use [name of drugs withheld] which is a 3rd generation antibiotic and they do not write the specific days, like for this many days.' (Nurse) 'As of now we have a problem in getting all departments together to get a good care of the patient. For example, in the emergency we see lot of cases which need to be consulted with different departments-interdepartmental consultation. [...] But at the moment it is very difficult to have an interdepartmental consultation.' (Ward manager)

'Patient safety in Bhutan, in my honest opinion, there isn't anything happening. We have some visiting professors and we have some health volunteers, they come in and they try to suggest and our staff, one or two maybe, try to take initiatives or people who have seen other hospital they think we need to do something. But it is ailing, because the system is not ready to accept anything. Right now, the health system is only considered about getting drugs and how many beds we can put and how many staff we can recruit but there is no check on how safe are the patients.' (Nurse)

$\begin{array}{ll}\begin{array}{l}\text { Poorly developed patient } \\ \text { safety incident reporting }\end{array} & \begin{array}{l}\text { 'I think that [incident reporting] is the weakest in the health system here. Keeping the data and } \\ \text { then recording and reporting is very, very poor in the healthcare system-be it in National Referral } \\ \text { Hospital or District Hospitals.' (Medical doctor) }\end{array} \\ \begin{array}{l}\text { Lack of patient education } \\ \text { on patient safety }\end{array} & \begin{array}{l}\text { 'I think in the hospital settings when we talk about safety of the patient and the factors, basically } \\ \text { patients were not educated on infection control so thereby they are not able to take care of their } \\ \text { own secretions like sputum or urine or even blood. So that is one factor that we are likely to have } \\ \text { infections.' (Health assistant) }\end{array}\end{array}$

'shortcuts' and carelessness). Examples included healthcare professionals not applying knowledge, despite knowing about patient safety measures, and not apportioning sufficient importance to Standard Operating Protocols and guidelines.

\section{System (organisational) factors}

Lack of resources

All categories of participants reported that shortage of staff (poor skill mix and staff-patient ratio) was the key contributing factor to diagnostic and medication errors. 
Also perceived to contribute to patient safety concerns was the lack of infrastructure. This included a lack of rooms to isolate patients with infectious diseases, to store clinical items (eg, sterilised packs), and to carry out procedures without disruption and contamination; lack of basic materials and equipment for infection control such as disinfectants, soaps and wound dressing supplies; dusty hospital surroundings; and absence of adequate systems to monitor hospital infection rates. Diagnostic errors were believed to be related to lack of adequate investigative resources (eg, laboratory reagents) and lack of functional and reliable diagnostic equipment.

\section{Lack of policies, guidelines and protocols on patient safety}

As a consequence of the lack of policies, guidelines, standard protocols and checklists, there was perceived variation in the management of patients across different hospitals and/or wards, with treating specialists and nurses not agreeing on treatment matters.

\section{Poor communication and collaboration}

Healthcare professionals failing to communicate verbally and not clearly documenting patient care were reported to contribute to patient safety concerns. For example, continuation of medications for unreasonable periods of time was perceived to have resulted from poor communication between doctors and nurses. Lack of clear communication with and provision of information to patients about their disease and treatment was reported to lead to poor compliance with treatment.

Lack of teamwork and collaboration among hospital departments and clinicians were perceived to be particularly problematic. Internal conflicts and 'tribal fights' were reported, with stakeholders trying to blame and 'pull each other's legs' (which in Bhutan is taken to mean 'belittling'), disrupting workplace harmony, respect and cooperation. Participants described difficulty coordinating members of departments due to lack of cooperation.

\section{Lack of management support and governance}

Some participants believed patient safety, as an agenda, had been overlooked by leaders and managers. Patient safety and risk management have not yet permeated into the Bhutanese healthcare system, and management was perceived as not yet ready to accept change.

\section{Poorly developed patient safety incident reporting}

Incident reporting processes were reportedly poorly developed. For instance, robust systems did not exist to record and report incidents and it was perceived that as a result the majority of incidents went unreported.

\section{Lack of patient education on patient safety}

Participants contended that patients are not educated about infection control and are not aware of how to take care of their own body secretions (sputum, urine and blood), increasing the risk of cross-infection. In addition, healthcare professionals' failure to inform and educate patients and the public about certain hospital functions and procedures, such as where to go in the event of emergencies and signs and symptoms of emergencies, were perceived to have contributed to patient mortality.

\section{Strategies to improve patient safety}

Participants identified six strategies to improve patient safety: instituting governance for patient safety, development/improvement of physical infrastructure/environment, providing adequate resources, providing patient safety training and education, promoting communication and information systems, and changing the attitudes and behaviour of healthcare professionals (themes and supporting quotes are provided in table 4).

\section{Instituting governance for patient safety}

Institution of patient safety governance was identified as an important strategy to improve patient safety processes and practices. Participants argued a hospital patient safety programme with a committee structure (eg, patient safety, mortality and clinical governance committees) reporting to the Ministry of Health would advance patient safety. To reduce risk of harm to patients, participants recommended implementation of robust policies, guidelines and protocols.

\section{Development/improvement of physical infrastructure/environment}

Participants highlighted the importance to patient safety of safe physical infrastructure and a safe environment. Safe infrastructure was characterised as strong buildings with adequate 'space'; good navigation systems (eg, signage); an inbuilt oxygen system, ramps, electric elevators, a ventilation system and good natural lighting. A safe environment was characterised as promoting physical safety, such as providing patients with an orientation on admission and maintaining cleanliness. The provision of equipment, such as wheel chairs and beds with side rails, was also deemed to be core elements of patient safety.

\section{Providing adequate resources}

Having adequate resources-including skilled and educated healthcare professionals, functional equipment and a constant supply of drugs-was considered critical to patient safety. Access to reliable laboratory facilities was considered necessary to facilitate correct patient diagnoses, treatment and management.

\section{Providing patient safety training and education for healthcare professionals}

Healthcare professionals (including doctors) were perceived to have inadequate knowledge about the concept and practice of patient safety. Developing clear guidelines, protocols and programmes to train and educate healthcare professionals about patient safety before they entered practice was considered essential to improving patient safety.

\section{Promoting communication and information systems}

Promoting communication and patient safety information systems was seen as important to patient safety. 
Table 4 Strategies to improve patient safety

Themes

Participant statements

'One thing is to constitute committees, especially relevant committees like clinical governance committees. [...] [...] We have to have regular updates, discussions [...] Certain bodies like quality control, mortality committee and clinical governance are very important.' (Medical doctor)

Development/improvement of physical infrastructure/environment

'[...] the infrastructure should be such that it promotes smooth flow of patients. Patients should not get confused. They should not get lost in a health facility. [...] the infrastructure should be in a normal condition, for example, the air flow, the exposure to sun should be good, so that we use minimum advance technologies like heating system, cooling system [...].' (Senior manager)

'[...] we need some trolleys, the oxygen and everything should be there and IV stands. We have the elevator here but it is not always working. So the patient sometimes gets locked inside the elevator. We need good electricity.' (Ward manager)

Providing adequate resources
Providing patient safety training and
education for healthcare professionals

'To improve patient safety in district hospital like ours, I think the first and foremost things we should have is enough staff. We should have enough equipment.' (Nurse)

'I think first and foremost most of the health workers don't have the concept of patient safety. Even doctors we are trained in different countries.' (Medical doctor)

Promoting communication and
information systems

'There should be proper communication between patient and the visitors and patient themselves, and also among healthcare workers because often a time there is a lot of miscommunication. This could ultimately pose a threat to patient safety.' (Nurse)

Changing the attitudes and behaviours of 'First and foremost is the notion that keeping patient safety is not the responsibility healthcare professionals of the managers or the leaders. Every individual should take each and every service or an activity in line with patient safety. [...] Patient safety has to be on our mind all the time.' (Medical doctor)

'It is not easy to change the attitude of people but maybe through our education system or through the training centre curriculum from day one till they leave the institute might have a role in changing the attitude and providing better safety to patient.' (Senior manager)

For participants, patient safety could be advanced by improving teamwork and interpersonal relationships among healthcare professionals, and by instituting mechanisms to monitor patient safety.

Changing the attitudes and behaviours of healthcare professionals Changing healthcare professionals' attitudes was considered critical to improving patient safety processes. Provision of education on patient safety in pre-service courses, and throughout employment, was considered essential to shaping the attitudes of and promoting respectful behaviour among healthcare professionals.

\section{DISCUSSION}

The Bhutanese government has prioritised improving the quality of its healthcare services. However, achieving the improvements desired is proving to be difficult. A key reason for this relates to the levels of complexity involved in providing high quality services, which cannot be addressed without a well-structured dedicated programme of patient safety. Arguably, one of the most striking findings of this study is the lack of a programme or infrastructure for capturing quantifiable and independently verifiable data on patient safety outcomes. Despite this, the study participants identified problems and patient safety outcomes that were commensurate with those identified in other countries. The mainstream patient safety issues and contributing factors (human and system factors) identified in this study were commensurate with those found in the UK, ${ }^{28}$ the USA, ${ }^{29}$ Australia, ${ }^{30}{ }^{31}$ Latin America, ${ }^{32}$ Thailand $^{33}$ and India. ${ }^{34-36}$ Participants identified medication errors, HAIs, surgical errors and postoperative complications, diagnostic errors, laboratory/ blood errors, fall injuries, information/communication errors and patient identification errors as key patient safety concerns in the Bhutanese healthcare system. Factors contributing to these concerns were perceived to include the system (latent failures) as well as human (staff) factors (slips, lapses and violations). Further, the strategies recommended by participants in this study are comparable to those tried and tested in other countries. ${ }^{37-39}$ Participants recommended instituting clinical governance, developing/improving physical infrastructure (including equipment), providing adequate human resources, providing patient safety education to healthcare professionals and patients, and promoting communication and information systems.

In light of the findings of this study, patient safety interventions in the Bhutanese healthcare system may need to be targeted at several points in the hierarchy, starting 
with policy development, and extending to assessment and management of risk, and the implementation of processes for reducing the incidence and impact of preventable adverse events. Specifically, patient safety improvement efforts need to focus on system/organisational factors. Addressing the system/organisational factors identified in this study would help to improve the overall healthcare system safety culture, which is now widely recognised in the patient safety literature as being critical to reducing the incidence and impact of preventable adverse events. ${ }^{40-42}$

One of the key recommendations made by participants in this study was to institute governance for patient safety: instituting patient safety monitoring committees and developing clear patient safety guidance documents. As suggested by this finding, a highly visible and functional patient safety committee/programme within Bhutan's Ministry of Health and guidance documents are needed, in conjunction with secure and adequate funding to make significant improvements in patient safety. Such a safety programme needs to include clear goals for safety; defining safety and risk management systems (including developing tools for identifying and analysing adverse events, and evaluating approaches taken to solve issues). Literature suggests that the institution of patient safety committees (including the establishment of national patient safety foundations and in-hospital patient safety committees) and patient safety guidance documents are imperative to enhancing patient safety in healthcare. ${ }^{43-45}$ The essential functions that patient safety committees can serve include overseeing patient safety programmes, developing expertise and managing resources. ${ }^{46-48}$ Development of clear patient safety guidance documents could improve patient safety in the Bhutanese healthcare system by establishing minimum levels of performance, maintaining consistency or uniformity across multiple individuals and organisations, setting expectations about what is to be achieved and fostering a shared set of beliefs, attitudes and norms, and prevent variation in clinical practice. ${ }^{43} 45-54$ Most importantly, development of adjunct guidance documents by the Bhutan Ministry of Health (with explicit process maps and decision trees detailing what healthcare professionals should do during the course of patient care) would help change the attitudes and behaviours of healthcare professionals.

As suggested by the findings of this study, development and/or improvement of physical infrastructure/environment (including equipment), providing adequate human resources, providing patient safety education to healthcare professionals and patients, and promoting communication and information systems, are also fundamental to improving patient safety. Research suggests that there is a positive relationship between these components and patient safety. For example, the lack of and/or poorly organised physical infrastructure or environment can have a significant impact on patient safety-including, for example, cross-infection and falls. ${ }^{385-60}$ The higher the ratio of qualified healthcare professionals to patients the better the patient safety outcomes-lower rates of medication errors and wound infections. ${ }^{61-68}$ Patient safety education and training programmes have been shown to increase healthcare professionals' ability to analyse and solve patient safety problems ${ }^{69}{ }^{70}$ Promoting communication and information systems such as information technology or decision support systems such as computerised physician order entry, which are designed to assist healthcare professionals in applying new information to patient care through the analysis of patient specific variables, are believed to improve communication on all levels. ${ }^{71-74}$ For instance, computerised devices like Personal Digital Assistant, which provide useful and accurate clinical practice guidelines and an alert system, have been found to be more efficient than their paperbased counterparts. ${ }^{75}$

On the basis of the findings of this study, and in keeping with the immediate priorities for national action on matters of patient safety, the cornerstone for a comprehensive strategy to improve patient safety in the Bhutanese healthcare system involves (1) a national focus on patient safety; (2) leadership, tools and protocols to enhance the knowledge base about safety; (3) patient safety governance; and (4) patient safety education and training.

\section{National focus on patient safety}

A national focus on patient safety entails setting national standards for patient safety; developing a strategic framework for patient safety; establishing a national patient safety programme; instituting a national patient safety governance committee; establishing well-trained and supported patient safety consultation teams (groups with specific responsibility for patient safety); and developing national policies on patient safety (service policy to establish resource allocation; practice policy that depicts minimum level of safety management and treatments; governance policy; sentinel event policy which provides clear guidance on appropriate responses to such situations; educational policy; and patient/staff abuse policy). As recommended by WHO, ${ }^{76}$ patient safety policy and strategy should be aligned with existing national priorities.

\section{Leadership for patient safety}

Leadership to promote patient safety involves launching patient safety initiatives in hospitals; allocating a budget for patient safety initiatives and ensuring they are adequately resourced; initiating change management programmes to build support for patient safety by the leaders of various health programmes; developing research agendas (to understand the nature and extent of patient safety concerns; implement effective strategies to improve patient safety and conduct research focused on teaching and learning of patient safety concerns and solutions); and establishing measures of performance (eg, developing and disseminating tools for identifying and analysing patient safety concerns and evaluating correction measures). 


\section{Patient safety governance}

Governance for patient safety requires development of a patient safety framework and policy; developing and implementing practice standards and guidelines for clinical practices and procedures; developing and implementing clinical bundles, pathways and protocols related to specific medical conditions and practices; developing and implementing checklists for different clinical practices, procedures and technologies/equipment; improving existing quality assurance processes; and developing clear job descriptions.

\section{Patient safety training and education}

Continuing patient safety training and education should be provided to all categories of healthcare staff (including cleaners and ward aides/assistants); This involves developing educational curricula on patient safety in institutes, universities and hospitals (for all categories of healthcare professionals undertaking certificate, diploma, higher degrees and continuing medical education) $;{ }^{77}$ developing and implementing standard protocols and guidelines for supervision and monitoring of students and junior clinicians; promoting dissemination of information on best practices and providing healthcare professionals with training in risk management.

In addition, development of a programme to identify and address specific patient safety issues is recommended. The mechanisms to assure, monitor and continually improve patient safety and quality of care must be built into the foundations of the health system. ${ }^{78}$ This includes addressing medication safety, surgical errors, diagnostic errors, laboratory/blood products, identification errors, HAIs and falls injuries by adopting six key methods of data collection and measurement, encompassing: patient outcome measurements (mortality and morbidity statistics); auditing of clinical practice, resource use and programme activities; measurement of patient satisfaction; systematic reporting and monitoring of patient safety data; and patient safety research. These processes help in detecting and monitoring a broad range of medical errors and solutions. ${ }^{50}$ 79-82 Strategies to address specific patient safety issues include, for example, patient identification by bracelet, correct labelling of medicines, implementation of unit-dose systems for medications, policies for blood transfusion and implementation of guidelines and/or protocols for the prevention of wrong patient, wrong site and wrong surgical procedure.

\section{Strengths and limitations}

A key strength of this study is the contribution it makes to a deeper awareness and understanding of the patient safety issues and concerns in the cultural context of Bhutan. Analysis of the data revealed the issues and concerns identified were commensurate with those experienced in other resource poor countries including the challenges of successfully addressing them. The main limitation of the study reported here is its reliance on patient safety concepts, theories and practices that have been developed and applied in high-income resource-rich nations. This, however, is also a strength of the study since one of its aims was to explore the 'fit' or otherwise of such a frame in under-resourced and data-poor nations, and to make meaningful comparisons. On the basis of the comparisons made, establishing a foundation for informing a locally adapted programme to address patient safety problems/issues identified in Bhutan has been rendered possible. A second limitation of the study relates to the large amount of data generated. As previously reported, ${ }^{26}$ decisions about inclusion and exclusion of data were informed by the consistency of findings across the disparate participant groups and the themes and/or issues that were pertinent to informing the patient safety concerns in the healthcare context of Bhutan. In this process it is possible that some material may have been lost.

\section{CONCLUSION}

This study pioneers the exploration of patient safety issues and concerns in Bhutan's healthcare system. The study has identified medication errors, HAIs, surgical errors and postoperative complications, diagnostic errors, laboratory/blood errors, fall injuries, communication errors and patient identification errors as key patient safety concerns. Factors contributing to these concerns were identified to include system as well as human factors. The strategies recommended by participants indicate that a system to mitigate risks caused by both human and system factors is required to improve patient safety in Bhutan's healthcare system.

Overall, this study has provided a basis on which future research and patient safety improvement strategies can be identified and developed. An immediate strategy, based on the findings of this study, would be to conceptualise and position patient safety as a priority for Bhutan's healthcare system and its leaders. Interventions need to target several points in the hierarchy, starting from policy development and extending to assessment and management of risk, and to reducing the incidence and impact of disruptive behaviours. Additionally, the provision of patient safety training and education for healthcare professionals and patients is required. These strategies would help improve overall safety by preventing adverse events.

Acknowledgements The authors thank Dr Megan-Jane Johnstone for her helpful comments on this article and for her support for this research.

Contributors RP conceived the study, collected and analysed the data. AMH supervised data collection and data analysis. Both authors prepared and approved this paper, designed the study and developed the study protocol.

Funding This research received no specific grant from any funding agency in the public, commercial or not-for-profit sectors.

Competing interests None declared.

Patient consent Not required.

Ethics approval Ethical approvals were obtained from the Research Ethics Board of Health, Ministry of Health, Bhutan (REBH/Approval/2012/018) and the Deakin University Human Research Ethics Committee (DUHREC 2012-221). 
Provenance and peer review Not commissioned; externally peer reviewed.

Data sharing statement № additional data are available.

Open access This is an open access article distributed in accordance with the Creative Commons Attribution Non Commercial (CC BY-NC 4.0) license, which permits others to distribute, remix, adapt, build upon this work non-commercially, and license their derivative works on different terms, provided the original work is properly cited, appropriate credit is given, any changes made indicated, and the use is non-commercial. See: http://creativecommons.org/licenses/by-nc/4.0/.

\section{REFERENCES}

1. Donaldson SL. Championing patient safety: going global. Qual Saf Health Care 2002;11:112.

2. World Health Organization. The international classification for patient safety key concepts and preferred terms. In: Final technical report for the conceptual framework for the international classification for patient safety, 2009. (accessed 1 Mar 2012).

3. World Health Organization. Patient safety research. 2012b http:// www.who.int/patientsafety/research/en/ (accessed 15 Apr 2012).

4. World Health Organization. Global priorities for patient safety research: better knowledge for safer care. 2009a http://whqlibdoc. who.int/publications/2009/9789241_eng.pdf (accessed 13 Apr 2012).

5. Jha AK, Prasopa-Plaizier N, Larizgoitia I, et al. Patient safety research: an overview of the global evidence. Qual Saf Health Care 2010;19:42-7.

6. Yoelao D, Mohan KP, Hamid HSA. A Review of Patient Safety in Thailand and Malaysia. Int J Behav Sci 2014;9:53-70.

7. Siddiqi S, Elasady R, Khorshid I, et al. Patient Safety Friendly Hospital Initiative: from evidence to action in seven developing country hospitals. Int J Qual Health Care 2012;24:144-51.

8. Hernandez K, Ramos E, Seas C, et al. Incidence of and risk factors for surgical-site infections in a Peruvian hospital. Infect Control Hosp Epidemiol 2005;26:473-7.

9. Charuluxananan S, Sriraj W, Lapisatepun W, et al. Drug errors from Thailand Anesthesia Incidents Study (Thai AIMS): analysis of 1,996 incident reports: 17AP2-8. Eur J Anaesthesiol 2012;6:541-7.

10. Jirapaet V, Jirapaet $\mathrm{K}$, Sopajaree $\mathrm{C}$. The nurses' experience of barriers to safe practice in the neonatal intensive care unit in Thailand. J Obstet Gynecol Neonatal Nurs 2006;35:746-54.

11. Taxis K, Barber N. Causes of intravenous medication errors: an ethnographic study. Qual Saf Health Care 2003;12:343-7.

12. Reason J. Understanding adverse events: human factors. Qual Health Care 1995;4:80-9.

13. Reason J. Human error: models and management. BMJ 2000;320:768-70.

14. Reason J. Beyond the organisational accident: the need for "error wisdom" on the frontline. Qual Saf Health Care 2004;13 Suppl 2:ii28-ii33.

15. Reason JT. Human error. Cambridge: Cambridge University Press, 1990.

16. Reason J. Safety in the operating theatre - Part 2: human error and organisational failure. Qual Saf Health Care 2005;14:56-60.

17. Cronenwett L, Sherwood G, Barnsteiner J, et al. Quality and safety education for nurses. Nurs Outlook 2007;55:122-31.

18. Cowan DT, Norman I, Coopamah VP. Competence in nursing practice: a controversial concept--a focused review of literature. Nurse Educ Today 2005;25:355-62.

19. Chuenjitwongsa S, Oliver RG, Bullock AD. Competence, competency-based education, and undergraduate dental education: a discussion paper. Eur J Dent Educ 2018;22:1-8.

20. Garside JR, Nhemachena JZ. A concept analysis of competence and its transition in nursing. Nurse Educ Today 2013;33:541-5.

21. Madigosky WS, Headrick LA, Nelson K, et al. Changing and sustaining medical students' knowledge, skills, and attitudes about patient safety and medical fallibility. Acad Med 2006;81:94-101.

22. Schnall R, Stone P, Currie L, et al. Development of a self-report instrument to measure patient safety attitudes, skills, and knowledge. J Nurs Scholarsh 2008;40:391-4.

23. Patton MQ. Qualitative research \& evaluation methods. 3rd edn. Thousand Oaks, California: Sage Publications, 2002.

24. Sandelowski M. Whatever happened to qualitative description? Res Nurs Health 2000;23:334-40.

25. Brink PJ, Wood MJ. Advanced design in nursing research. 2nd edn. California: Sage, 1998.

26. Pelzang R. Patient safety issues and concerns in Bhutan's healthcare system: a qualitative study. Deakin University 2016.

27. Smith J, Firth J. Qualitative data analysis: the framework approach Nurse Res 2011;18:52-62.
28. Healey F, Scobie S, Oliver D, et al. Falls in English and Welsh hospitals: a national observational study based on retrospective analysis of 12 months of patient safety incident reports. Qual Saf Health Care 2008;17:424-30.

29. Linden JV, Wagner K, Voytovich AE, et al. Transfusion errors in New York State: an analysis of 10 years' experience. Transfusion 2000;40:1207-13.

30. Kable AK, Gibberd RW, Spigelman AD. Adverse events in surgical patients in Australia. Int J Qual Health Care 2002;14:269-76.

31. Nichols P, Copeland TS, Craib IA, et al. Learning from error: identifying contributory causes of medication errors in an Australian hospital. Med J Aust 2008;188:276-9.

32. Aranaz-Andres JM, Aibar-Remon C, Limon-Ramirez R, et al. Prevalence of adverse events in the hospitals of five Latin American countries: results of the 'Iberoamerican study of adverse events' (IBEAS). BMJ Qual Saf 2011;20:1043-51.

33. Asavaroengchai S, Sriratanaban J, Hiransuthikul N, et al. Identifying adverse events in hospitalized patients using global trigger tool in Thailand. Asian Biomed 2009;3:545-50.

34. Datta P, Rani H, Chauhan R, et al. Health-care-associated infections: Risk factors and epidemiology from an intensive care unit in Northern India. Indian J Anaesth 2014;58:30-5.

35. Harrison R, Cohen AW, Walton M. Patient safety and quality of care in developing countries in Southeast Asia: a systematic literature review. Int J Qual Health Care 2015;27:240-54.

36. Kumar S, Chaudhary S. Medical errors and consequent adverse events in critically ill surgical patients in a tertiary care teaching hospital in Delhi. J Emerg Trauma Shock 2009;2:80-4.

37. Elkin PL, Gorman PN. Continuing medical education and patient safety: an agenda for lifelong learning. J Am Med Inform Assoc 2002:9:128S-32.

38. Hignett S, Lu J. Space to care and treat safely in acute hospitals: recommendations from 1866 to 2008. Appl Ergon 2010;41:666-73.

39. Reiling J, Breckbill C, Murphy M, et al. Facility designing around patient safety and its effect on nursing. Nurs Econ 2003;21:143-7.

40. Morello RT, Lowthian JA, Barker AL, et al. Strategies for improving patient safety culture in hospitals: a systematic review. BMJ Qual Saf 2013;22:11-18

41. Vogus TJ, Weick KE, Sutcliffe KM. Doing no harm: enabling, enacting, and elaborating a culture of safety in health care. Acad Manag Perspect 2010;24:60-77.

42. Zaheer S, Ginsburg L, Chuang YT, et al. Patient safety climate (PSC) perceptions of frontline staff in acute care hospitals: examining the role of ease of reporting, unit norms of openness, and participative leadership. Health Care Manage Rev 2015;40:13-23.

43. Kohn LT, Corrigan JM, Donaldson MS. To err is human: Building a safer health system. Washington D.C.: National Academy Press, 2000.

44. Clinical Excellence Commission. Patient safety research: A review of the technical literature The centre for Clinical Research, University of New South Wales, Sydney Donald Hindle. Jeffrey Braithwaite and Rick Ledema 2005

45. Adibi $\mathrm{H}$, Khalesi N, Ravaghi $\mathrm{H}$, et al. Development of an effective risk management system in a teaching hospital. Journal of Diabetes \& Metabolic Disorders 2012;11:15.

46. Boddington $\mathrm{R}$, Arthur $\mathrm{H}$, Cummings $\mathrm{D}$, et al. Team Resource Management and patient safety: A team focused approach to clinical governance. Clin Govern Int J 2006;11:58-68.

47. Sage WM, Gallagher TH, Armstrong S, et al. How policy makers can smooth the way for communication-and- resolution programs. Health Aff 2014;33:11-19.

48. Scott I. What are the most effective strategies for improving quality and safety of health care? Intern Med J 2009;39:389-400.

49. Szymanska M, Ryan CA, Murphy BP. Introducing random safety audits (RSA) in a neonatal intensive care unit (NICU). Ir Med J 2011;104:114-7.

50. Ursprung R, Gray JE, Edwards WH, et al. Real time patient safety audits: improving safety every day. Qual Saf Health Care 2005;14:284-9.

51. McDonald R, Waring J, Harrison S, et al. Rules and guidelines in clinical practice: a qualitative study in operating theatres of doctors' and nurses' views. Qual Saf Health Care 2005;14:290-4.

52. Classen DC, Kilbridge PM. The roles and responsibility of physicians to improve patient safety within health care delivery systems. Acad Med 2002;77:963-72.

53. Institute of Medicine. Crossing the quality chasm: a new health system for the 21st century. Washington, D.C: National Academies Press, 2001.

54. Nolan TW. System changes to improve patient safety. BMJ 2000;320:771-3. 
55. Flynn EA, Barker KN, Gibson JT, et al. Relationships between ambient sounds and the accuracy of pharmacists' prescription-filling performance. Hum Factors 1996;38:614-22.

56. Mahmood A, Chaudhury H, Valente M. Nurses' perceptions of how physical environment affects medication errors in acute care settings. Appl Nurs Res 2011;24:229-37.

57. Muto CA, Jernigan JA, Ostrowsky BE, et al. SHEA guideline for preventing nosocomial transmission of multidrug-resistant strains of Staphylococcus aureus and enterococcus. Infect Control Hosp Epidemiol 2003;24:362-86.

58. Reiling JG, Knutzen BL, Wallen TK, et al. Enhancing the traditional hospital design process: a focus on patient safety. Jt Comm J Qual Saf 2004;30:115-24.

59. Rubin HR. Status report--an investigation to determine whether the built environment affects patients' medical outcomes. J Healthc Des 1998;10:11-13.

60. Walsh-Sukys M, Reitenbach A, Hudson-Barr D, et al. Reducing light and sound in the neonatal intensive care unit: an evaluation of patient safety, staff satisfaction and costs. J Perinatol 2001;21:230-5.

61. Archibald LK, Manning ML, Bell LM, et al. Patient density, nurseto-patient ratio and nosocomial infection risk in a pediatric cardiac intensive care unit. Pediatr Infect Dis J 1997;16:1045-8.

62. Hugonnet S, Chevrolet JC, Pittet D. The effect of workload on infection risk in critically ill patients. Crit Care Med 2007;35:76-81.

63. Lichtig LK, Knauf RA, Milholland DK. Some impacts of nursing on acute care hospital outcomes. J Nurs Adm 1999;29:25-33.

64. Nantsupawat A, Nantsupawat R, Kulnaviktikul W, et al. Relationship between nurse staffing levels and nurse outcomes in community hospitals, Thailand. Nurs Health Sci 2015;17.

65. Needleman J, Buerhaus P, Mattke S, et al. Nurse-staffing levels and the quality of care in hospitals. N Engl J Med 2002;346:1715-22.

66. Robertson $\mathrm{RH}$, Hassan M. Staffing intensity, skill mix and mortality outcomes: the case of chronic obstructive lung disease. Health Serv Manage Res 1999;12:258-68.

67. Stegenga J, Bell E, Matlow A. The role of nurse understaffing in nosocomial viral gastrointestinal infections on a general pediatrics ward. Infect Control Hosp Epidemiol 2002;23:133-6.

68. McGillis HL, Doran D, Pink GH, et al. nursing hours, and patient safety outcomes. J Nurs Adm 2004;34:41-5.

69. Patey R, Flin R, Cuthbertson $\mathrm{BH}$, et al. Patient safety: helping medical students understand error in healthcare. Qual Saf Health Care 2007;16:256-9.
70. Chopra V, Gesink BJ, de Jong J, et al. Does training on an anaesthesia simulator lead to improvement in performance? $\mathrm{Br} J$ Anaesth 1994;73:293-7.

71. Koppel R, Metlay JP, Cohen A, et al. Role of computerized physician order entry systems in facilitating medication errors. JAMA 2005;293:1197-203.

72. Bates DW, Kuperman G, Teich JM. Computerized physician order entry and quality of care. Qual Manag Health Care 1994;2:18-27.

73. Bates DW, Spell N, Cullen DJ, et al. The costs of adverse drug events in hospitalized patients. Adverse Drug Events Prevention Study Group. JAMA 1997;277:307-11.

74. Wong J, Beglaryan H. Strategies for hospitals to improve patient safety: a review of the research. 2004. http://www.psnet.ahrq.gov/ resource.aspx?resourcelD=1341 (accessed 6 August 2014).

75. VanDenKerkhof EG, Goldstein DH, Lane J, et al. Using a personal digital assistant enhances gathering of patient data on an acute pain management service: a pilot study. Can J Anaesth 2003;50:368-75.

76. World Health Organization. A handbook for National quality policy and strategy (NQPS): a practical approach to development of policy and strategy on improving quality of health care, co-developed by the World Health Organization and countries embarking on national quality initiatives 2018. 2018. https://www.who.int/servicedeliverys afety/areas/qhc/NQPS-webinar2017.pdf?ua=1 (accessed 3 Jun 2018).

77. Pelzang R, Hutchinson AM. How Is Patient Safety Understood by Healthcare Professionals? The Case of Bhutan. J Patient Saf 2017:1 (accessed 22 April 2818).

78. World Health Organization. Delivering quality health services: a global imperative for universal health coverage. 2018. https://scholar. google.com.au/scholar?hl=en\&as_sdt=0\%2C5\&q=Delivering+ quality+health+services+A+global+imperative+for+universal+health+ coverage+by+OECD\%2FWorld+Bank\%2FWHO+report+launched+ last+week+at+the+World+Health+Assembly\&btnG= (accessed 2 Jun 2018).

79. Garrouste-Orgeas M, Philippart F, Bruel C, et al. Overview of medical errors and adverse events. Ann Intensive Care 2012;2:2-10.

80. Jarernsiripornkul N, Krska J, Capps PA, et al. Patient reporting of potential adverse drug reactions: a methodological study. $\mathrm{Br} \mathrm{J}$ Clin Pharmacol 2002;53:318-25.

81. Piotrowski MM, Hinshaw DB. The safety checklist program: creating a culture of safety in intensive care units. Jt Comm J Qual Improv 2002;28:306-15.

82. Wolff AM, Bourke J. Reducing medical errors: a practical guide. Med $J$ Aust 2000;173:247-51. 